\title{
ESTÁGIO CURRICULAR SUPERVISIONADO NA FORMAÇÃO DE PROFESSORES EM EDUCAÇÃO FÍSICA: UMA ANÁLISE DA LEGISLAÇÃO A PARTIR DA RESOLUÇÃO CFE N 03/1987¹
}

\author{
Arestides Pereira da Silva Júnior \\ Universidade Estadual do Oeste do Paraná, Marechal Candido Rondon, Paraná, Brasil \\ Patric Paludett Flores \\ Universidade Estadual de Maringá, Maringá, Paraná, Brasil \\ Camila Rinaldi Bisconsini \\ Universidade Estadual de Maringá, Maringá, Paraná, Brasil \\ Ana Luíza Barbosa Anversa \\ Universidade Estadual de Maringá, Maringá, Paraná, Brasil \\ Amauri Aparecido Bássoli de Oliveira \\ Universidade Estadual de Maringá, Maringá, Paraná, Brasil
}

\begin{abstract}
Resumo
O Estágio Curricular Supervisionado (ECS) na formação de professores de Educação Física $(\mathrm{EF})$, ao longo das últimas três décadas, vem passando por transformações no sentido de fortalecer essa etapa da formação inicial, buscando aproximação do acadêmico ao seu futuro campo profissional e ao cotidiano docente. Dessa forma, o objetivo da pesquisa foi, por meio de uma análise documental, apresentar e discutir as principais leis que sustentam e subsidiam o ECS na formação de professores de EF no Brasil, a partir da Resolução CFE n 03/1987. No campo burocrático e documental, constataram-se avanços importantes que favoreceram a organização e estruturação do ECS como um momento fundamental no processo de ensino e aprendizagem na formação dos futuros professores de EF.
\end{abstract}

Palavras-chave: Legislação; Estágio Curricular Supervisionado; Educação Física; Licenciatura.

\section{Introdução}

O Estágio Curricular Supervisionado ${ }^{2}$ (ECS) é um componente indispensável no processo de formação inicial, que oportuniza ao futuro professor a possibilidade de exercer a atividade profissional em seu campo real de intervenção. O ECS deve possibilitar aos

\footnotetext{
${ }^{1} \mathrm{O}$ presente trabalho recebeu apoio financeiro da Fundação Araucária de Apoio ao Desenvolvimento Científico e Tecnológico do Estado do Paraná e da Coordenação de Aperfeiçoamento de Pessoal de Nível Superior (CAPES) por meio de bolsas de estudo (Nível Doutorado).

${ }^{2}$ Nos documentos analisados nessa pesquisa, verificou-se a utilização de diferentes denominações para o estágio obrigatório na licenciatura. No entanto, no intuito de padronização, atualização e facilitação no entendimento, adotou-se nesse texto a utilização do termo Estágio Curricular Supervisionado (conforme nomenclatura utilizada na Resolução CNE/CP n 02/2015) para referir-se ao estágio, estágio supervisionado e/ou estágio curricular.
} 
estudantes o cumprimento de uma atividade teórico-prática, crítico-reflexiva, respaldada pelo conhecimento teórico e da realidade de atuação, procurando articular ensino, pesquisa e extensão (ANDRADE; RESENDE, 2010; PIMENTA; LIMA, 2012).

$\mathrm{Na}$ formação de professores, é preciso que o futuro docente entenda o ECS como um processo que extrapola contatos pontuais com a escola, percebendo essa ação para além do cumprimento de tarefas curriculares (MORAES et al., 2008). Assim, o estagiário deve ser considerado, como protagonista consciente na sua atuação, de forma que as ações desenvolvidas ao longo do estágio valorizem uma postura crítica e reflexiva no exercício de suas ações teórico-práticas no contexto escolar.

No curso de licenciatura em Educação Física (EF) não é diferente, o ECS deve ser entendido como uma etapa que privilegia o processo de reflexão crítica do aluno frente à realidade com a qual está interagindo, aliado aos conhecimentos e competências necessários para a prática pedagógica (BRASIL, 2002; CAMPOS, 1999; SCHERER, 2008). Veiga (2004) aponta que o estágio se constitui como um lugar da construção da profissão, do profissionalismo e da profissionalização do professor/profissional como responsável pela sua prática docente/interventiva e consciente de seu papel social.

No entanto, tal perspectiva, que valoriza a práxis interventiva, a postura crítica e outros aspectos de uma participação envolvente do estagiário, não era apreciada na legislação precursora do ECS na formação de professores. Por exemplo, o Parecer CFE n 292/1962 foi o pioneiro a definir a Prática de Ensino sob forma de ECS, estabelecendo-o como componente curricular obrigatório a ser cumprido em todos os cursos de licenciatura. Essa intervenção deveria ocorrer em escolas da rede de ensino com duração de um semestre letivo, e era vista como um momento de aplicar na prática a teoria aprendida na universidade. Além disso, Andrade e Resende (2010) afirmam que essa ideia de prática estava muito relacionada a um treinamento, que era baseado no modelo tecnicista. Todavia, vale salientar que o Parecer CFE $n^{\circ} 292 / 1962$ não foi o responsável por introduzir tal modelo, mas de certa forma, a sua organização e estruturação eram condizentes com essa perspectiva de ensino.

$\mathrm{Na}$ década de 1970, outro documento que merece destaque é o Parecer CFE $\mathrm{n}^{\circ}$ 349/1972, que procurou valorizar a Didática como disciplina responsável por proporcionar momentos de encontro do discente com a escola, com vivências de ensino. Entretanto, na visão de Pimenta (1994), apesar do intuito de fortalecer a associação e aproximação da teoria com a prática na atuação docente, o referido Parecer parece não ter alcançado o resultado esperado, uma vez que tratou a didática como teoria e o estágio como prática. Além disso, este Parecer propôs uma reprodução de modelos que valorizavam uma realidade positiva, mascarando, por vezes, os problemas existentes no cotidiano escolar.

No final da década de 1970 e início de 1980, mantinha-se a dicotomia entre a formação pedagógica e a formação específica (modelo 3+1), que surgiu na década de 1930, de modo que muitas críticas aos modelos educacionais apareceram, e por consequência ao ECS. Nesse sentido, em grande parte pela luta dos educadores atuantes na década de 1980, algumas reformas educacionais e na legislação foram indispensáveis para acompanhar um novo período, marcado pela globalização do capital, mudanças no mundo do trabalho e na comunicação (ANDRADE; RESENDE, 2010). Entre as normativas criadas nesse período, destaca-se a Lei no 9.394/1996 - Lei de Diretrizes e Bases da Educação Nacional (LDBEN). De acordo com Gordo, Santos e Moreira (2014, p.60),

Essa nova LDB que entrou em vigor em 1996 e permanece até os dias atuais, trouxe consigo mudanças importantes para o sistema educacional, mas antes de ser aprovada passou por muitos debates, discussões e emendas, que vinham acontecendo desde a promulgação da Constituição de 1988. 
Na EF este panorama não foi diferente, já que se passou a ter uma nova visão em relação aos encaminhamentos didáticos e pedagógicos da área, fase esta, marcada por tendências críticas, reflexivas e participativas (DARIDO; SANCHES NETO, 2005). Nessa mesma direção, o ECS no curso de formação de professores de EF, ao longo das últimas três décadas, passou por transformações no sentido de tentar fortalecer esta etapa da formação inicial e acompanhar o movimento que repensava o ensino, inclusive no que se refere à formação inicial de professores. Entretanto, mesmo com os "possíveis avanços" teóricos, conceituais e de legislação que indicam, valorizam e enaltecem o ECS na formação dos professores, Neira (2012), pensando na realidade da EF especificamente, afirma que normalmente se observa uma desvalorização das disciplinas responsáveis pela prática pedagógica, inclusive aquelas direcionadas à organização do ECS. Entende-se que há um tratamento marginal das experiências formativas vividas fora da universidade e a falta de relação entre escola e Instituição de Ensino Superior (IES).

Nessa direção, questiona-se: Até que ponto a legislação (Leis, Pareceres $e$ Resoluções) subsidia as ações do ECS na EF escolar? Quais foram os avanços e retrocessos referentes à legislação do ECS na formação de professores de EF? Para discutir e buscar respostas a estas questões adotou-se como ponto de corte para esta pesquisa a legislação posterior a Resolução CFE ${ }^{\circ}$ 03/1987, já que esta traçou encaminhamentos para a separação entre a licenciatura e o bacharelado na área da EF.

Atualmente, as pesquisas realizadas sobre o ECS na EF têm abordado diversas temáticas, principalmente no que se refere à relação entre teoria e prática, ao papel dos agentes do estágio, ao planejamento, à avaliação, e à relação entre escola e IES (BENITES; SOUZA NETO, 2011; KRUG et al., 2013; MOLETTA et al., 2013; SANTOS; SOUZA; BARBOSA, 2013; ZOTOVICI et al., 2013). No entanto, observou-se, no levantamento bibliográfico consultado, apenas a pesquisa de Montiel e Pereira (2011) que abordou de forma específica a legislação do ECS no âmbito da formação de professores de EF. Outra pesquisa da área que merece destaque é a de Benites, Souza Neto e Hunger (2008), que analisa o processo de constituição histórica das Diretrizes Curriculares na formação de professores de $\mathrm{EF}$, mas que não é específico do ECS. No contexto geral da educação, podemos citar algumas pesquisas que analisam os aspectos legais do ECS na formação de professores, mas que também são restritos, como por exemplo: Carvalho (2001) e Andrade e Resende (2010).

Dessa forma, a presente pesquisa objetiva apresentar e discutir as principais leis que sustentam e subsidiam o ECS na formação de professores de EF no Brasil, a partir da Resolução CFE n 03/1987.

A perspectiva de avaliar constantemente os aspectos legais e normativos no contexto educacional e, neste caso, o ECS na formação de professores de EF, configura-se um processo relevante, visto que a legislação não é algo fixo, ao contrário, ela se altera ao longo dos anos conforme a necessidade e/ou interesses das comunidades envolvidas, ou ainda por interesses políticos. Neste sentido, a partir do pressuposto de que o ECS em EF se constitui como um componente para a formação inicial, conhecer a sua transformação histórica e se manter atualizado quanto às questões legais e normativas se torna primordial.

\section{Metodologia}

Esta pesquisa é caracterizada como descritiva documental (MARKONI; LAKATOS, 2010) e aborda a legislação para a formação de professores de EF, tecendo ligações com o ECS.

No trabalho são abordados os seguintes documentos da legislação referente ao propósito da pesquisa: a) Resolução CFE $n^{\circ}$ 03/1987, que inicialmente possibilitou a formação em EF nas habilitações licenciatura e bacharelado; b) Lei n 9.394/1996 - Lei de 
Diretrizes e Bases da Educação Nacional (LDBEN), na qual a EF passa a ser considerada componente curricular e não mais atividade; c) Lei Federal $n^{\circ} 9.696 / 1998$ que regulamentou a profissão e o profissional de EF; d) Resolução CNE/CP $n^{\circ}$ 01/2002, que estabeleceu as Diretrizes Curriculares Nacionais para a Formação de Professores da Educação Básica, em nível superior, curso de licenciatura, de graduação plena; e) Resolução CNE/CP n 02/2002, que instituiu a duração e a carga horária dos cursos de licenciatura, de graduação plena, de formação de professores da Educação Básica em nível superior; f) Resolução CNE/CES n 07/2004, que estabeleceu as Diretrizes Curriculares Nacionais para os cursos de graduação em EF, em nível superior de graduação plena; g) Lei $n^{\circ} 11.788 / 2008$, a qual dispõe sobre o estágio de estudantes; e h) Resolução CNE/CP n 02/2015.

$\mathrm{O}$ tratamento de análise dos documentos se deu a partir de um enfoque qualitativo (BOGDAN; BIKLEN, 2013), no qual a indução, a criticidade e a discussão com o referencial teórico específico foram premissas fundamentais para levantar questionamentos, posicionamentos e conclusões acerca da legislação do ECS na formação de professores de EF. Inicialmente os documentos foram lidos na íntegra, em seguida foram realizados encontros entre os pesquisadores com o intuito de discutir os principais aspectos evidenciados e relacionados ao ECS na formação inicial em EF. Esses encaminhamentos possibilitaram a elaboração de categorias de análise a partir dos objetivos do estudo. Por fim, as informações foram inseridas cronologicamente no texto e discutidas com o referencial teórico específico da temática.

\section{Resultados e discussão}

Neste artigo, as discussões do ECS na formação de professores de EF partem da Resolução CFE n ${ }^{\circ}$ 03/1987, que garantiu à EF a oferta de uma formação universitária sem a necessidade de se atender legalmente a um currículo mínimo, provocando mudanças curriculares, a começar pela possibilidade de se optar por licenciatura e/ou bacharelado. Além disso, estimulou a estruturação do ECS com duração mínima de um semestre letivo.

Essa Resolução pode ser considerada uma demarcação para a área de estudos e formação profissional em EF, ao possibilitar a formação nas duas habilitações. Conforme Benites, Souza Neto e Hunger (2008, p. 345) "essa mudança provocou um divisor de águas no sentido de se produzir a profissão e a área de conhecimento Educação Física". No entanto, considerando a abrangência do campo de atuação, a maioria dos cursos, naquele momento, optou por uma formação em que os profissionais eram formados para atuar tanto no campo escolar (Educação Infantil, Ensino Fundamental e Médio) quanto no não escolar (academias, clubes, centros comunitários/condomínios etc.).

No Art. $1^{\circ}$ da Resolução CFE $n^{\circ}$ 03/1987 é apontado que a formação em EF seria feita em curso de graduação que conferiria o título de bacharel e/ou licenciado, e de acordo com o Artigo $4^{\circ}$, este curso teria uma duração mínima de quatro anos e máxima de sete anos, compreendendo uma carga horária mínima de 2.880 horas/aula, dentro das quais deveria ser contemplado o ECS. Especificamente no Artigo $5^{\circ}$, cita que o ECS, com a duração mínima de um semestre letivo, é obrigatório tanto nas licenciaturas quanto nos bacharelados, devendo para estes, ser complementado com a apresentação de uma monografia. Assim, nessa proposta, as IES tiveram mais autonomia e flexibilidade para a organização do curso, inclusive do ECS.

É preciso esclarecer ainda que a Resolução CFE $n^{\circ} 03 / 1987^{3}$ destaca e explica brevemente algumas áreas de conhecimento: filosófico, do ser humano, da sociedade, e

\footnotetext{
${ }^{3}$ O Parecer CNE/CES no 215 de 11 de março de 1987, já dispunha sobre a reestruturação dos cursos de graduação em EF, sua nova caracterização, mínimos de duração e conteúdo. Este Parecer subsidiou a elaboração da Resolução CFE n ${ }^{\circ}$ 03/1987.
} 
técnico; seguindo as duas partes que deveriam ser contempladas nos currículos de graduação plena em EF; a formação geral (humanística e técnica) e aprofundamento de conhecimentos, procurando garantir uma formação que permitisse a aquisição de conhecimentos e técnicas para atuar nos dois contextos de forma crítica, ética, reflexiva, inovadora e democrática. No entanto, esse encaminhamento trouxe à tona dois modelos de formação: o tradicionaldesportivo, estruturado nas práticas esportivas; e o técnico-científico, prevalecendo a fundamentação de um corpo de conhecimento (BETTI; BETTI, 1996).

De acordo com Oliveira (2006), a possibilidade da formação do licenciado em simultâneo ao do bacharel acabou sendo mal administrada, principalmente no momento de se elencar os conhecimentos identificadores das duas formações para compor um núcleo comum. Com isso, as instituições passaram a ofertar duas formações com habilitações distintas, entretanto, no dia a dia das aulas na graduação não se explicitavam diferenças entre as disciplinas do bacharelado e da licenciatura. Nessa organização curricular o ECS não era realizado nos mesmos espaços, o que provocavam desafios aos estagiários, já que a formação era muito parecida para as duas habilitações, mas o estágio se dava em espaços de intervenção diferenciados. Esse processo ficou conhecido como "dois em um", ou seja, duas habilitações em um único curso, fragilizando, momentaneamente, a distinção entre as formações, pois não se teve clareza de papéis e corpo de conhecimento específico para cada uma delas.

Contudo, percebemos que a área da EF ganhou significativamente com a promulgação dessa Resolução, pois as diversas IES e seus docentes precisaram se debruçar sobre a organização curricular e tudo que envolve esse processo, a formação do profissional ganha um ano, aprofunda novas áreas de conhecimento na formação, estimula que os futuros profissionais se vinculem à produção e disseminação do conhecimento pelo estímulo à produção monográfica de final de curso, além de outros tantos aspectos que repercutiram numa nova postura profissional e representatividade social. $\mathrm{O}$ ponto divergente e pouco explorado resultante dessa Resolução foi a questão da separação entre licenciatura e bacharelado, tanto é que isso não impactou significativamente nas IES que ofertavam o curso no momento. Para os ECS não houve mudança significativa, pois o mesmo manteve sua forma de desenvolvimento e diversificação.

No início da década de 1990, havia uma discussão acalorada em todo o Brasil sobre sua Lei maior da Educação, a LDBEN que define todo o quadro de educação para o País. Havendo uma alteração nessa Lei, todas as demais vinculadas devem ser reeditadas e reorganizadas de acordo com as especificidades. Depois de ajustes técnicos e políticos na LDBEN $n^{\circ}$ 9.394/96, houve a sua promulgação. Destaca-se que os traços de autonomia curricular propostos pela Resolução CFE $\mathrm{n}^{\circ}$ 03/1987, foram assegurados a todas as IES e áreas por meio desta nova Lei, avalizando que cada instituição adequasse seu currículo à sua realidade local. Tais readequações foram de grande valia, já que de acordo com Krahe (2000), o Brasil, devido a sua grande extensão territorial, apresenta vários subgrupos culturais. Logo, essa mobilidade garante a execução de ajustes curriculares de acordo com a região e grupo de população a ser atendido.

A LDBEN $\mathrm{n}^{\circ}$ 9.394/1996 apresentou transformações importantes em termos estruturais fundamentais do contexto educacional, e isso foi constatado também em relação ao ECS. Dentre estes, ressalta-se, sobretudo: "a associação entre teorias e práticas, inclusive mediante a capacitação em serviço" (Art. 61, § I); a garantia de que a "formação docente, exceto para a educação superior, deve incluir prática de ensino" (Art. 65); bem como, "os sistemas de ensino estabelecerão as normas para realização dos estágios dos alunos regularmente matriculados no ensino médio ou superior em sua jurisdição" (Art. 82).

Dessa forma, na LDBEN n ${ }^{\circ}$ 9.394/1996 destacou-se a necessidade da superação de modelos desarticulados e que valorizassem a qualidade e competência na formação dos futuros professores, dando-lhes condições para exercer a sua formação inicial de forma 
articulada com o contexto profissional (ANDRADE; RESENDE, 2010). Entretanto, a referida Lei não pôde garantir que nos cursos de formação docente o ECS se caracterizasse como o caminho para efetivar essa aproximação dos conteúdos do curso com a realidade escolar, já que as ações dependem diretamente dos agentes envolvidos, neste caso, os docentes dos cursos.

Entende-se que a LDBEN n ${ }^{\circ}$ 9.394/1996 destaca muitos pontos a serem contemplados na rotina da educação, na tentativa de aproximar as diferentes instâncias do ensino no papel de seus agentes (professores, alunos, comunidade e outros) e das estruturas que comportam e participam das ações. Ainda traz possibilidades de avanços para alcançar um maior número de pessoas envolvidas com a Educação Básica e com o Ensino Superior. Apesar da referida Lei não aprofundar pontos específicos sobre o ECS e a relação deste com a EF, acredita-se que apresenta questões inerentes às discussões aqui propostas, sobretudo em relação à Prática de Ensino, organização dos estágios e formação docente.

Por fazer parte da legislação que envolve a $\mathrm{EF}$, também é possível destacar a Lei $\mathrm{n}^{\circ}$ 9.696/1998, que dispõe sobre a regulamentação da profissão de EF e cria os respectivos Conselho Federal e Conselhos Regionais da área (CONFEF, CREF). Esse processo de regulamentação favoreceu a valorização da EF em relação às demais áreas do conhecimento e culminou na ampliação das possibilidades de intervenção do profissional, resultando, de acordo com Oliveira (2000) e com a Lei $n^{\circ}$ 046/2002 do CONFEF, em novos campos de atuação, em que se destacam saúde, lazer, esporte, empresa, associações esportivas, condomínios, logradouros públicos, praças e parque, entre outros. Vale ressaltar que não foi objetivo da Lei $\mathrm{n}^{\circ}$ 9.696/1998 discutir o ECS na formação de professores de EF, mas por se tratar de uma referência para a área no que diz respeito à atuação profissional, fomentou reflexões acerca do processo e efetividade das ações quanto ao atendimento das múltiplas ações incumbidas aos profissionais de EF, refletindo na escola, e por extensão, no ECS.

Com a nova LDBEN em vigor, as consequências para o desenvolvimento da educação brasileira continuam na efervescência, ou seja, as proposições de mudanças em discussões acaloradas (CARVALHO, 2001; BENITES, SOUZA NETO; HUNGER, 2008; ANDRADE; RESENDE, 2010). Uma das mais fortes foi em relação à formação do professor da Educação Básica. Muitos documentos foram produzidos e acabou culminando na apresentação de uma formação específica para esse profissional, inicialmente por meio do Parecer CNE/CP $\mathrm{n}^{\circ}$ 09/2001, que resultou nas Resoluções CNE/CP n ${ }^{\circ} 01$ e 02/2002.

Ressalta-se aqui a importância do Parecer CNE/CP $\mathrm{n}^{\circ}$ 09/2001, que identifica a fragilidade do processo formativo, demonstrando a distância entre o que é estudado no campo acadêmico e o que é posto em prática no campo de atuação (realidade da escola). Assim traz no bojo a argumentação desta nova proposição que destaca o conceito de simetria invertida em que "o preparo do professor, por ocorrer em lugar similar àquele em que vai atuar, demanda consistência entre o que faz na formação e o que dele se espera" (BRASIL, 2001, p. 2). Este Parecer estabelece ainda que a licenciatura tenha objetivos próprios em relação ao bacharelado, constituindo-se em um projeto específico. Todas as áreas que oferecem a possibilidade da licenciatura deveriam se enquadrar nessa nova organização determinada pelas Resoluções específicas a partir de 2002.

Em relação à Resolução CNE/CP n ${ }^{\circ}$ 01/2002, o ECS passa a constituir-se como um espaço interdisciplinar de formação, com a finalidade de favorecer e valorizar o conhecimento da realidade profissional (no caso da escola), por meio de um "processo de estudo, análise, problematização, teorização, reflexão, proposição de alternativas, intervenção e redimensionamento da ação" (ANDRADE; RESENDE, 2010, p.243). Este aspecto se torna de suma importância para a EF, considerando a especificidade da disciplina e o seu contexto de atuação, que são distintos dos demais componentes curriculares, o que lhe proporciona uma 
identidade particular. Ainda conforme a Resolução CNE/CP n $^{\circ}$ 01/2002, o ECS deve ser avaliado conjuntamente pela escola formadora e a escola campo de estágio.

No que se refere à Resolução CNE/CP n ${ }^{\circ}$ 02/2002, percebe-se que esta contribui para uma adequada sistematização das ações do ECS, já que se define a carga horária mínima exigida de 400 horas de ECS a partir do início da segunda metade do curso, direcionando a organização das ações (ao menos aquelas burocráticas) para os cursos de licenciatura. Andrade e Resende (2010) afirmam que esta regulamentação é positiva no que tange à organização e estruturação dos cursos de formação de professores. No entanto, os autores fazem uma crítica em relação à proposta curricular com carga horária mínima estabelecida, pois entendem que isso fragmenta e favorece a separação entre teoria e prática. Por outro lado, o estabelecimento de carga-horária na legislação favorece um entendimento mais adequado dos limites e exigências gerais a todas as IES, o que seguramente tem impacto no contexto pedagógico e repercussão também na realização do ECS, principalmente na $\mathrm{EF}$, que tem no seu contexto histórico a cultura da dicotomia entre o fazer e o pensar.

Embora a Resolução CNE/CP $n^{\circ}$ 02/2002 tenha possibilitado avanços frente à organização e estruturação do ECS, a duração mínima de 2.800 horas, e não inferior a três anos letivos para conclusão dos cursos de licenciatura, apresentou reflexos negativos no processo de ensino e aprendizagem dos futuros professores, pois no intuito de diminuir os custos, muitas IES optaram por ofertar os cursos em duração mínima, o que teve implicação na realização do ECS, que por sua vez foi estruturado de forma a condensar sua carga horária a partir do início da segunda metade do curso.

Ainda acerca da Resolução CNE/CP $n^{\circ}$ 02/2002, destaca-se a Prática como Componente Curricular (PCC) com 400 horas a serem distribuídas ao longo da formação inicial de professores. Na mesma Resolução, o ECS também é apresentado com 400 horas a serem cumpridas a partir da segunda metade do curso de licenciatura. Ou seja, a PCC e o ECS possuíam a mesma carga horária, no entanto, a primeira deveria iniciar no primeiro ano do curso, enquanto o segundo partia da segunda metade do processo. Desse modo, os primeiros contatos do discente com a escola se dariam por meio das práticas curriculares, em que os professores do curso organizariam momentos de aproximação dos conteúdos pelos quais são responsáveis com a realidade da Educação Básica, como uma oportunidade de efetivar a relação teoria-prática. Essas práticas poderiam minimizar os desafios iniciais do discente no ECS, muitas vezes causados pelo desconhecimento da escola e seus agentes. Entendemos, pois, que essa Resolução oportuniza pensar a formação inicial de professores em constante comunicação com a escola, em que a PCC e o ECS se interligam, e juntos se caracterizam como fio condutor no Projeto Pedagógico dos Cursos.

Segundo Andrade e Resende (2010) e Benites (2012), na PCC deve ocorrer uma relação constante entre teoria e prática, propiciando uma discussão contínua entre o saber e o fazer. Essa imbricação visa permitir ao futuro professor buscar significados para o trabalho de gestão, de administração e de ensino, além de capacitá-lo para a resolução de situações vivenciadas no ambiente escolar, numa perspectiva interdisciplinar. Prevê, ainda, que a prática seja desenvolvida com ênfase nos procedimentos de observação e reflexão, visando à atuação em situações contextualizadas com o registro dessas observações realizadas e a resolução de situações-problema.

Dessa forma, entendemos que a PCC se relaciona diretamente com o ECS, pois aproxima o futuro professor do seu campo de atuação desde o começo da formação inicial, e nesse caso, no ECS os discentes poderão recorrer a uma diversidade de elementos acerca do espaço escolar e de seus agentes, o que facilita e enriquece o planejamento e desenvolvimento das regências exigidas no período do estágio. A partir dessa perspectiva de formação, a PCC e o ECS são reconhecidos como o tempo de aprendizagem em que se estabelece uma relação 
pedagógica entre o professor em ambiente de trabalho e o aluno estagiário, fortalecendo e estreitando a relação teoria e prática.

Os novos direcionamentos para as licenciaturas acabaram refletindo fortemente nos processos de formação em EF, efervescendo discussões sobre a oferta da licenciatura e do bacharelado de forma separada. Este novo formato da formação recebeu o caráter definitivo por meio da Resolução CNE/CES n ${ }^{\circ}$ 07/2004, que abordou algumas releituras dos objetivos da formação em relação ao campo de atuação profissional, em especial na readequação de conhecimentos e habilidades. Nessa Resolução, instituem-se as Diretrizes Curriculares Nacionais para o curso de graduação em EF, em nível superior de graduação plena, além de estabelecer orientações específicas para a licenciatura plena em EF, nos termos definidos nas Diretrizes Curriculares Nacionais para a Formação de Professores da Educação Básica.

De acordo com Benites, Souza Neto e Hunger (2008), a Resolução CNE/CES n ${ }^{\circ}$ 07/2004 procurou quebrar algumas barreiras da Resolução CFE $n^{\circ}$ 03/1987 no que se refere às definições, concepção do campo e organização curricular, com o intuito de delimitar o que se compreende por EF, bem como, o perfil do profissional que se espera formar. Assim, podese afirmar que a referida Lei, embora não tenha uma relação direta com o ECS na formação de professores de EF, foi importante para demarcar a área de conhecimento e de intervenção da EF.

Com a Resolução, a EF passou a ser definida como uma área de conhecimento e intervenção acadêmico-profissional, assumindo o movimento humano como objeto de estudo, abrangendo os exercícios físicos, a ginástica, os jogos, esportes, lutas/arte marcial e dança como conteúdos. Hunger et al. (2009, p.88) destacam que:

\begin{abstract}
Os saberes foram redimensionados e articulados em formação ampliada, contemplando as dimensões: Relação Ser Humano-Sociedade, Biológica do Corpo Humano, Produção do Conhecimento Científico e Tecnológico; e Formação Específica relacionada aos conhecimentos identificadores da Educação Física, contemplando as dimensões: Culturais do Movimento Humano, TécnicoInstrumental e Didático-Pedagógico.
\end{abstract}

A partir da homologação dessa Resolução, ficou estabelecido que a licenciatura se voltasse à formação de professores para atuar na Educação Básica, direcionando sua ação interventiva para a disciplina como componente curricular. Já no bacharelado, o profissional será preparado para analisar a realidade social, intervindo, em busca da adoção de um estilo saudável e uma vida fisicamente ativa, por meio de diferentes manifestações corporais.

Outra norma importante que se propõe ser analisada neste artigo é a Lei $n^{\circ}$ 11.788/2008, a qual dispõe sobre o estágio de estudantes. Esta Lei define novas regras sobre o estágio na formação profissional, mesmo que não exclusivas na formação de professores. De acordo com essa Lei, o estágio supervisionado é entendido como ato educativo aos futuros profissionais, neste caso em particular os professores, que devem ser orientados por um docente da IES e supervisionados por um professor da escola em todas as atividades realizadas, desde o planejamento, desenvolvimento até a avaliação. Essa Lei estabelece que o estágio seja um componente do Projeto Pedagógico do Curso e que ocorra na forma de obrigatório ou não obrigatório.

Segundo a mesma Lei, cabe à IES celebrar o termo de compromisso com o educando e a parte concedente; indicar o professor orientador, responsável pelo acompanhamento e avaliação das atividades; bem como exigir a apresentação de relatório das atividades realizadas. Já à parte concedente cabe ofertar instalações adequadas para que o estagiário desenvolva as atividades de aprendizagem; indicar um funcionário de seu quadro para orientar e supervisionar até 10 estagiários; contratar seguro contra acidentes pessoais em favor do aluno; e enviar relatório das atividades do estagiário. 
Esta Lei é considerada um avanço, pois normatiza, organiza e dá amparo legal às questões referentes ao estágio, desde as obrigações das IES, das partes concedentes e do estagiário (SOUZA NETO et al., 2012). Assim, é possível inferir que tal organização no contexto burocrático possibilitará uma intervenção mais coerente, coesa e adequada no contexto pedagógico, principalmente na $\mathrm{EF}$, que apresenta uma configuração peculiar devido às instalações para as aulas, aos materiais pedagógicos e a dinâmica das atividades.

A Resolução CNE/CP $\mathrm{n}^{\circ}$ 02/2015, que reformula, atualiza e amplia as Diretrizes Curriculares Nacionais para a formação inicial em nível superior e para a formação continuada, apresenta o ECS no Art. 13 e $\S 6^{\circ}$, como "componente obrigatório da organização curricular das licenciaturas, sendo uma atividade específica intrinsicamente articulada com a prática e com as demais atividades de trabalho acadêmico" (BRASIL, 2015). É importante ressaltar que essa Resolução contém normativas gerais ao processo de formação de professores, não sendo específica da EF.

Uma alteração significativa a partir da Resolução CNE/CP n ${ }^{\circ}$ 02/2015 diz respeito à carga horária dos cursos de licenciatura, que é de 3.200 horas com duração não inferior a quatro anos, quando comparada à Resolução CNE/CP n ${ }^{\circ}$ 02/2002, em que a carga horária total das licenciaturas era de 2.800 horas. Quanto à carga horária do ECS, esta Resolução não apresentou alterações em relação à Resolução CNE/CP n $^{\circ}$ 02/2002, permanecendo com as 400 horas na área de formação e atuação na Educação Básica. No entanto, não há mais o indicativo de que o ECS seja realizado apenas a partir do início da segunda metade do curso, ou seja, a partir da Resolução CNE/CP $\mathrm{n}^{\circ}$ 02/2015 ele pode ocorrer em qualquer período, conforme o Projeto Pedagógico do Curso da IES. Neste documento, a PCC também mantém a carga horária de 400 horas distribuídas ao longo da formação inicial. Nesse sentido, ressaltase a necessidade da estruturação e organização do curso que possibilite a realização do ECS em consonância e coerência com as atividades formativas e a PCC, de forma a possibilitar o seu efetivo funcionamento, numa relação de colaboração entre universidade e escola (AROEIRA, 2014).

Outro aspecto destacado na Resolução CNE/CP n 02/2015 é a apresentação dos princípios de carga horária aos cursos de formação pedagógica para graduados não licenciados e os cursos de segunda licenciatura, nos quais a carga horária do ECS deve ser de 300 horas.

Por fim, considerando os aspectos legais e normativos analisados nessa pesquisa, há um notório movimento de correções, definições e adequações na legislação, fortalecendo no campo burocrático o ECS na formação dos professores de EF. Entretanto, não é possível afirmar que os aspectos legais apresentados consolidaram uma formação inicial docente mais condizente com a realidade escolar, uma vez que não foi objetivo dessa pesquisa investigar tal relação. Assim, sugere-se que outras pesquisas sejam realizadas para verificar o impacto das mudanças legais acerca da formação de professores no dia a dia dos cursos de licenciatura de EF.

\section{Considerações finais}

A presente pesquisa, com base na análise da legislação do ECS (Leis, Pareceres e Resoluções) a partir da Resolução CFE $n^{\circ}$ 03/1987, possibilitou verificar avanços importantes no campo burocrático e documental e suas possíveis relações/implicações com aspectos organizacionais e estruturais do ECS na formação dos professores de EF.

Dentre os principais aspectos positivos constatados nos documentos analisados, destacam-se: a legalização, a normatização e regulamentação do ECS para a formação de professores de EF; a delimitação da área de conhecimento e intervenção da EF; a visão de que o ECS não é o único momento em que o estudante faz imersão no campo de atuação; a 
valorização da PCC como um elemento importante na formação inicial e como suporte para o desenvolvimento do estágio; a especificidade da disciplina de EF e o contexto de atuação devem ser considerados e enfatizados na realização do ECS, e a compreensão de que o ECS não é um produto final, mas sim um processo, já que também é considerado um momento de produção/ressignificação de conhecimentos direcionados aos anseios locais.

Dessa forma, considerando os documentos analisados e o referencial teórico discutido nessa pesquisa, pode-se afirmar que houve progressos e delineamentos importantes na legislação do ECS referente à formação de professores de EF. Por um lado, houve um avanço natural e esperado, considerando as transformações e os progressos do contexto educacional como um todo e da área da EF, uma vez que o cenário histórico e cultural foi modificado ao longo das últimas três décadas. Por outro lado, é notório que a legislação garantiu melhorias na regulamentação e direcionamento do ECS, ao legitimar a importância desse componente curricular na formação inicial, construindo possivelmente uma implicação favorável para a prática pedagógica dos futuros professores.

Entretanto, ainda observam-se carências na legislação em relação à consolidação do verdadeiro objetivo do ECS nos cursos de formação de professores. Nota-se a falta de uma organização que contemple e articule os demais componentes curriculares com o ECS e que legitime o papel da escola, campo de estágio, como a instituição responsável pela formação inicial dos futuros professores de EF.

\title{
SUPERVISED ACADEMIC TRAINING FOR PHYSICAL EDUCATION TEACHERS: AN ANALYSIS OF THE LEGISLATION THROUGH RESOLUTION CFE N $^{\circ}$ 03/1987
}

\begin{abstract}
Throughout the last three decades, the Supervised Academic Training (ECS) for Physical Education teachers has been transformed to enhance this stage of initial training bringing scholars closer to their prospective professional field and to educational routine. In this context, the objective of this research was to develop a document analysis in order to present and discuss the major laws that support and subsidize the Supervised Academic Training for Physical Education teachers in Brazil, through Resolution CFE $\mathrm{n}^{\circ}$ 03/1987. In the bureaucratic and documental fields we verified important advances favoring the organization and structuring of the ECS as a key point in the process of teaching and learning for the training of future Physical Education teachers.
\end{abstract}

Keywords: Legislation; Supervised Academic Training; Physical Education; Educator Licensure.

\section{PRÁCTICA CURRICULAR SUPERVISADA EN LA FORMACIÓN DE PROFESORES EN EDUCACIÓN FÍSICA: UN ANÁLISIS DE LA LEGISLACIÓN A PARTIR DE LA RESOLUCIÓN CFE Nº 03/1987}

\section{Resumen}

La Práctica Curricular Supervisada (PCS) en la formación de profesores de Educación Física (EF), a lo largo de las últimas tres décadas, ha pasado por transformaciones en el sentido de fortalecer esta etapa de la formación inicial, aproximando el académico de su futuro campo profesional y del cotidiano docente. De esa manera, el objetivo de la investigación fue, por medio de un análisis documental, presentar y discutir las principales leyes que sostienen y subsidian la PCS en la formación de profesores de EF en el Brasil, a partir de la Resolución CFE ${ }^{\circ}$ 03/1987. En el campo burocrático y documental, se constataron avances importantes 
que favorecieron la organización y estructuración de la PCS como un momento fundamental en el proceso de enseñanza y aprendizaje en la formación de los futuros profesores de EF.

Palabras clave: Legislación; Práctica Curricular Supervisada; Educación Física; Licenciatura.

\section{Referências}

ANDRADE, R. C. R.; RESENDE, M. R. Aspectos legais do estágio na formação de professores: uma retrospectiva histórica. Educação em Perspectiva, Viçosa, v. 1, n. 2, p. 230-252, jul./dez. 2010.

AROEIRA, K. P. Estágio Supervisionado e possibilidades para uma formação com vínculos colaborativos entre a universidade e a escola. In: ALMEIDA, M. I.; PIMENTA, S. G. (Org.). Estágio Supervisionado na formação docente: educação básica e educação de jovens e adultos. São Paulo: Cortez, 2014.

BENITES, L. C. O professor-colaborador no Estágio Curricular Supervisionado em Educação Física: perfil, papel e potencialidades. 2012. 180f. Tese (Doutorado em Ciências da Motricidade) - Universidade Estadual Paulista Júlio de Mesquita Filho, Rio Claro, 2012.

BENITES, L. C.; SOUZA NETO, S. Educação física, professores e estudantes: a escolha da docência como profissão e os saberes que lhe são constitutivos. Pensar a Prática, Goiânia, v. 14, n. 2, p. 1-11, maio/ago. 2011.

BENITES, L. C.; SOUZA NETO, S.; HUNGER, D. O processo de constituição histórica das diretrizes curriculares na formação de professores de Educação Física. Educação e Pesquisa, São Paulo, v.34, n.2, p. 343-360, maio/ago. 2008.

BETTI, I. C. R.; BETTI, M. Novas perspectivas na formação profissional de educação física. In. Motriz, Rio Claro, v. 2, n. 1, p. 10-15, 1996.

BOGDAN, R.; BIKLEN, S. Investigação qualitativa em educação: uma introdução à teoria e aos métodos. Porto Editora: Porto, 2013.

BRASIL. Ministério da Educação. Parecer n. ${ }^{0}$ 292, de 14 de novembro de 1962.

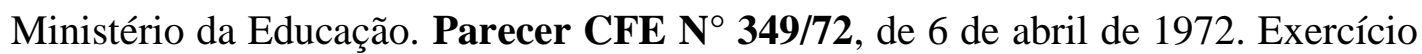
do magistério em $1 .^{\circ}$ grau, habilitação específica de $2 .^{\circ}$ grau. Disponível em: <http://www.soleis.adv.br/>. Acesso em: 16 jan. 2015.

. Conselho Federal de Educação. Resolução no . 03 de 16 de junho de 1987.

. Conselho Nacional de Educação e Conselho de Ensino Superior. Parecer no 215 de 11 de março de 1987.

. Lei n. 9.394/96, de 20 de dezembro de 1996. Estabelece as diretrizes e bases da educação nacional. Diário Oficial da União, Brasília, DF, 23 dez. 1996. p. 27894. 
Lei no 9.696, de $1^{\circ}$ de setembro de 1998. Dispõe sobre a regulamentação da Profissão de Educação Física e cria os respectivos Conselho Federal e Conselhos Regionais de Educação Física. Diário Oficial da União, Brasília, DF, 2 set. 1998.

Ministério da Educação. Conselho Nacional de Educação. Parecer CNE/CP 09/2001. Diretrizes Curriculares Nacionais para a Formação de Professores da Educação Básica, em nível superior, curso de licenciatura, de graduação plena. Brasília, DF, 2001.

. Ministério da Educação. Resolução CNE/CP 1, de 18 de fevereiro de 2002. Diário Oficial da União, Brasília, 2002a.

Ministério da Educação. Resolução CNE/CP 2, de 19 de fevereiro de 2002. Diário Oficial da União, Brasília, 2002b.

. Conselho Nacional de Educação - Conselho Pleno, Resolução CNE/CP n 7, de 18 de Março de 2004.

. Ministério da Educação. Lei no $\mathbf{0} \mathbf{1 1 . 7 8 8}$ de 25 de setembro de 2008.

Ministério da Educação. Resolução CNE/CP 2, de $1^{\circ}$ de julho de 2015. Diário Oficial da União, Brasília, 2015.

CAMPOS, M. Z. A questão da licenciatura em Educação Física: a transição à prática profissional I. 1999. 191 f. Dissertação (Mestrado em Educação Física) - Universidade Estadual de Campinas, Faculdade de Educação Física. Campinas, 1999.

CARVALHO, A. M. P. A influência das mudanças da legislação na formação dos professores: as 300 horas de estágio supervisionado. Ciência \& Educação, v.7, n.1, p.113$122,2001$.

DARIDO, S. C.; et al. (Org.). Educação física na escola: implicações para a prática pedagógica. Rio de Janeiro: Guanabara Koogan, 2005. p. 50-61.

GORDO, M. do E. S. C.; SANTOS, M. A. R. dos; MOREIRA, W. W. A história da Educação Física no Brasil e suas bases legais. Belém: Editora Açaí, 2014.

HUNGER, D. A. C. F.; et al..Formação acadêmica em Educação Física: "corpos" (docente e discente) de conhecimentos fragmentados. Motriz, Rio Claro, v. 15, n. 1, p. 79-91, jan./mar. 2009 .

KRAHE, E. D. As reformas na estrutura curricular de licenciaturas na década de 90: um estudo de caso comparativo- Tese (doutorado) Programa de Pós-Graduação em Educação, Faculdade de Educação, Universidade Federal do Rio Grande do Sul, UFRGS (Brasil) UMCE (Chile). Porto Alegre: 2000.

KRUG, H. N.; et al. Necessidades formativas de acadêmicos de licenciatura em Educação Física em situação de estágio curricular supervisionado. Revista Ibero-Americana de Estudos em Educação, Araraquara, v. 8, n. 1, 2013. p. 252-274. 
MARCONI, M. A.; LAKATOS, E. M. Fundamentos de metodologia científica. 7. ed. São Paulo: Atlas, 2010.

MOLETTA, A. F.; et al. Momentos marcantes do estágio curricular supervisionado na formação de professores de educação física. Pensar a Prática, Goiânia, v. 16, n. 3, jul./set. 2013.

MONTIEL, F. C.; PEREIRA, F. M. Problemas evidenciados na operacionalização das 400 horas de estágio curricular supervisionado. R. da Educação Física/UEM, Maringá, v. 22, n. 3, p. 421-432, 3. trim. 2011.

MORAES, E. V.; et al. O estágio supervisionado nos cursos de graduação em Educação Física: um desafio presente nesta formação. Dialogia, São Paulo, v. 7, n. 2, p. 199-209, 2008.

NEIRA, M. G. Proposições para o estágio disciplinar na formação de professores de Educação Física. In: NASCIMENTO, J. V.; FARIAS, G. O. (Org). Construção da identidade profissional em Educação Física: da formação a intervenção. Florianópolis: Ed. da UDESC, 2012.

OLIVEIRA, A.A.B. Mercado de trabalho em Educação Física e a formação profissional: breves reflexões. Revista Brasileira Ciência e Movimento, v. 8, n.4, p.45-50, 2000.

OLIVEIRA, A. A. B. A formação profissional em educação física: legislação, limites e possibilidades. In: SOUZA NETO S.; HUNGER D. (Org.). Formação profissional em educação física: estudos e pesquisas. Rio Claro: Biblioética, 2006. p.17-32.

PIMENTA, S. G.; LIMA, M. S. L. Estágio e docência. 7. ed. São Paulo: Cortez, 2012.

PIMENTA, S. G. O estágio na formação de professores: Unidade teoria e prática? São Paulo: Cortez, 1994.

SANTOS, R. G.; SOUZA, A. L.; BARBOSA, F. N. M. Estágio supervisionado I: O desafio da avaliação nas aulas de Educação Física escolar. Pensar a Prática, Goiânia, v. 16, n. 2, p. 320618, abr./jun. 2013.

SCHERER, A. O desafio da mudança na formação inicial de professores: o estágio curricular no curso de licenciatura em Educação Física. 2008. 210 f. Tese (Doutorado em Educação) - Universidade Federal do Rio Grande do Sul. Faculdade de Educação. Porto Alegre, 2008.

SOUZA NETO, S.; et al, C. O estágio supervisionado como prática profissional, área de conhecimento e locus de construção da identidade do professor de Educação Física. In: NASCIMENTO, J. V.; FARIAS, G. O. (Org). Construção da identidade profissional em Educação Física: da formação a intervenção. Florianópolis: Ed. da UDESC, 2012.

VEIGA, I. P. A. Educação básica e educação superior projeto político pedagógico. Campinas, SP: Papirus, 2004. 
ZOTOVICI, S. A.; et al. Reflexões sobre o estágio supervisionado no curso de licenciatura em Educação Física: entre a teoria e a prática. Pensar a Prática, Goiânia, v. 16, n. 2, abr./jun. 2013.

Recebido em: 06/04/2015

Revisado em: 24/11/2015

Aprovado em: 18/01/2016

Endereço para correspondência:

arestidesjunior2000@yahoo.com.br

Arestides Pereira da Silva Júnior

Universidade Estadual do Oeste do Paraná, Conselho de Ensino, Pesquisa e Extensão.

Rua Pernambuco, n.1.777

Centro

85960-000 - Marechal Candido Rondon, PR - Brasil 